\title{
Burden of Asthma in Elderly Japanese Patients: Using Hospital-Based Administrative Claims Data
}

\author{
Keiko Sato (D) - Takeo Ishii (D) - Toshihiko Kaise
}

Received: March 17, 2020 / Published online: June 5, 2020

(C) The Author(s) 2020

\begin{abstract}
Introduction: Data are lacking on severe asthma burden in elderly people in Japan. We assessed the prevalence and clinical/economic burden of severe asthma and asthma-related hospitalizations in elderly and younger Japanese patients.

Methods: This retrospective study analyzed outpatient claims data and inpatient hospital discharge records among patients aged $\geq 15$ years with asthma (defined as $\geq 2$ prescriptions of inhaled corticosteroids [ICS] or ICS/long-acting beta-agonists [LABA]) between 1 July 2014 and 30 June 2017. We analyzed the outpatient visit assessment population with severe asthma ( $\geq 240$-day prescription of highdose ICS and $\geq 90$-day prescription of $\geq 1$ additional controllers) and the asthma-related hospitalization population $(\geq 1$ hospital
\end{abstract}

Digital Features To view digital features for this article go to https://doi.org/10.6084/m9.figshare.12301379.

Electronic supplementary material The online version of this article (https://doi.org/10.1007/s41030020-00121-w) contains supplementary material, which is available to authorized users.

K. Sato $(\bowtie) \cdot T$. Kaise

Value Evidence Outcomes, Japan Development

Division, GSK K.K., Tokyo, Japan

e-mail: keiko.2.sato@gsk.com

T. Ishii

Japan Respiratory Medical Affairs, Development and Medical Affairs, GSK K.K., Tokyo, Japan
admission[S] with a primary diagnosis of asthma/status asthmaticus and use of systemic corticosteroids) over a 1-year observation period before the date of each patient's latest asthma prescription or asthma-related hospitalization within the study period. The primary outcome was the proportion of elderly ( $\geq 65$ years) and younger (15-39 and 40-64 years) patients among the outpatient visit assessment population. Secondary outcomes included outpatient and inpatient characteristics, asthma-related healthcare resource utilization, and asthma-associated costs, by age group.

Results: Of the outpatient visit assessment population $(n=35,742), 4211$ had severe asthma, with the prevalence of $8.2 \%, 12.8 \%$, and $12.4 \%$ for the $15-39,40-64$, and $\geq 65$ years age groups, respectively. Elderly versus younger outpatients with severe asthma had higher cumulative oral corticosteroid doses. Among both outpatient visit assessment population and hospitalization assessment population, elderly versus younger outpatients with severe asthma or asthma-related hospitalizations had more comorbidities, required more biological, hematological, immunological, and microbiological tests, and incurred higher asthma-associated costs.

Conclusions: In addition to reaffirming the higher prevalence of severe asthma in Japanese patients $\geq 40$ years versus those $<40$ years of age, our results demonstrated higher clinical and economic burden in elderly versus younger patients. 
Keywords: Asthma; Burden; Comorbidities; Costs; Elderly; Healthcare resource utilization; Japan; Prevalence; Severe asthma; Real world

\section{Key Summary Points}

Why carry out this study?

Japan has an ever-increasing elderly population, and severe asthma is generally considered to be more common in elderly compared with younger patients.

However, the disease burden of severe asthma is not well documented in elderly Japanese patients.

This study assessed the prevalence, as well as the clinical and economic burden of severe asthma in Japanese patients according to age (15-39, 40-64, and $\geq 65$ years).

\section{What was learned from the study?}

In addition to reaffirming that severe asthma is more common among Japanese patients

$\geq 40$ years than those $<40$ years of age, the results demonstrated that elderly Japanese patients ( $\geq 65$ years) generally have a higher clinical and economic asthma burden than younger Japanese patients.

This highlights a need for treatment options that help to improve asthma control in elderly patients with severe asthma in Japan, which may reduce the need for specialist healthcare and associated costs for these patients.

\section{INTRODUCTION}

Asthma is a heterogeneous disease characterized by chronic airway inflammation and respiratory symptoms [1], and is estimated to affect approximately 339 million people worldwide [2]. Disease severity varies between patients. International (European Respiratory Society/
American Thoracic Society) guidelines define severe asthma as asthma that requires treatment with high-dose inhaled corticosteroids (ICS) plus a second controller medication and/or systemic corticosteroids for $\geq 50 \%$ of the year to maintain asthma control, or asthma that remains uncontrolled despite these treatments. The likelihood of developing severe asthma increases with age, which is an independent risk factor for the development of severe asthma that has a stronger impact than other factors such as disease duration [3]. Severe asthma is therefore generally thought to affect a greater proportion of elderly patients than younger patients.

Severe asthma is estimated to affect $5-10 \%$ of the global asthma population and $8-11 \%$ of people with asthma in Japan [4, 5]. A recent retrospective database study found an association between severe asthma and a significant disease burden in Japanese workers and their family members aged 15-65 years [6]. This study also suggests that Japanese patients with severe asthma are generally older than those with mild or moderate asthma. However, the claims database used for this analysis and for other recent studies was limited only to employees, who are likely to retire around 60-65 years of age and therefore drop out from the database $[4,6]$. Furthermore, severe asthma places a disproportionately high burden on healthcare systems; in a number of geographic regions, it has been shown that the rates of healthcare resource utilization (HCRU) and healthcare costs are higher for patients with severe asthma compared with those with non-severe asthma [7-9].

Since the older population in Japan is growing and the life expectancy in Japan is now 82 years of age for both males and females $[10,11]$, it is particularly important to improve our understanding of the clinical and economic burden of diseases such as severe asthma in elderly Japanese patients. However, the prevalence and disease burden of severe asthma in a real-world setting is currently not well documented for elderly patients in Japan. This study aimed to determine the prevalence and burden of severe asthma in Japanese patients $\geq 65$ years of age, compared with that 
in younger patients, using real-world data from outpatient administrative claims. Moreover, the burden of asthma-related hospitalization by age group was assessed using inpatient claims data.

\section{METHODS}

\section{Study Design and Data Source}

The data source of this study (GlaxoSmithKline (GSK) ID: HO-16-17890) was a hospital-based database provided by Medical Data Vision (MDV) Co., Ltd (Tokyo, Japan). The MDV database is a hospital-based database including hospitals throughout Japan participating in the national diagnosis-procedure combination (DPC) payment system [12]. Because the DPC payment system applies to only hospitalization records, the MDV database covers only hospitals with inpatient facilities and thus does not include outpatient clinics. All the patients covered by this study regularly visited DPC hospitals for treatment of asthma. Although the Japanese healthcare system allows free access to medical services, there may be more severe cases in hospitals, where more specialists are available, than in outpatient clinics in general. Data were collected during the study period, from 1 July 2014 to 30 June 2017 . Since a hospital-based database was used for patient identification, we could not analyze patients who visited or who were hospitalized in other medical facilities. Patients with severe asthma were identified using outpatient claims. The burden of hospitalization was analyzed using inpatient claims, not linked with outpatient claims. Thus, the burden of asthma-related hospitalization was not categorized by the severity of asthma.

\section{Compliance with Ethics Guidelines}

The study used anonymized data, therefore, no patient consent was requested, as this is not required for such studies in Japan. Ethical approval was obtained from the Ethics Review Committee at the Kitamachi Clinic (1-1-3
Kichijojikitamachi, Musashino City, Tokyo 180-0001).

\section{Study Population}

Eligible patients were $\geq 15$ years of age (defined as adults according to a regulation in Japan) at the time of their first claim with an asthma or status asthmaticus diagnosis code (International Classification of Diseases, 10th Revision (ICD-10) codes J45 and J46, respectively) during the study period. Patients had to have continuous enrollment in the MDV database for $\geq 1$ year prior to the asthma index date and within the study period and no evidence of any other respiratory diagnosis or diagnosis of a non-respiratory condition that may also have required systemic corticosteroids (Table S1 in the electronic supplementary material). A summary of all codes used to identify clinical conditions, asthma medications, and medical services from the claims data is provided in the supplementary materials (Table S2).

The 1-year observation period, during which all outcomes were assessed, began 1 year prior to the asthma index date and finished before the asthma index date.

Inpatient administrative claims data and hospital discharge records were also used to identify patients with asthma-related hospitalizations, defined as inpatient hospital admissions with a primary diagnosis of asthma/status asthmaticus and with use of systemic (intravenous or oral) corticosteroids during the observation period (hospitalization assessment population). The asthma-related hospitalization index date was defined as the start date of latest asthma-related hospitalization for each patient (the end of which must have been within the study period). Although patients with asthmarelated hospitalizations based on inpatient claims were analyzed as those with severe asthma, outpatient visit data and hospitalization data were not linked in the analysis. The severity of asthma in each inpatient claim was not assessed. 


\section{Outcomes and Assessments}

For all outcomes, patients were divided into three age categories: 15-39, 40-64, and $\geq 65$ years of age. The primary outcome was the prevalence of severe asthma among the outpatients based on outpatient visit data (outpatient visit assessment population). For this population, the index date was the date of latest prescription of asthma medication within the study period for each patient. Asthma medication prescriptions recorded in the outpatient administrative claims data were used to identify patients with asthma ( $\geq 2$ prescriptions of ICS or ICS/long-acting beta-agonists [LABA]), and among them, patients who had severe asthma (defined as $\geq 240$-day prescription of high-dose ICS and $\geq 90$-day prescription of $\geq 1$ additional controllers) within the 1-year observation period. In medical insurance claim data in Japan, the regimen for ICS is not available, but the number of products is available; the number of prescriptions days of high-dose ICS or ICS/LABA was calculated using the following equation using a reference value specified in the 2017 Japanese Guideline for Adult Asthma [13].

Number of prescriptions days of high-dose ICS or ICS/LABA = [number of prescribed products per year] $\times$ [dose $(\mu \mathrm{g})$ of ICS per product] $/$ [reference value $(\mu \mathrm{g})$ for high-dose ICS per day].

For this outcome, patients were further divided into nine age categories: 15-19, 20-29, $30-39,40-49$, 50-59, 60-69, 70-79, 80-89, and $\geq 90$ years of age. Secondary outcomes analyzed included demographics, clinical features, asthma-related HCRU, and asthma-associated costs for Japanese patients with asthma. In this study, asthma-related outpatient visits (office hours), asthma pulmonary function tests, and laboratory tests for the outpatient visit assessment population; and asthma-related hospitalization, pulmonary function tests, and laboratory tests for the hospitalization assessment population were recorded. Direct asthmarelated costs per patient included the costs of management, medical procedures, and laboratory tests, and were stratified by the following categories: scheduled and unscheduled outpatient visits, medication, and hospitalization. Direct costs were calculated based on medical service fee points in claims ( 1 medical fee point $=10$ Japanese Yen $[¥])$; costs were not adjusted for inflation. Among these secondary outcomes, asthma-related HCRU and costs were additionally assessed for patients 15-19, 20-29, 30-39, 40-49, 50-59, 60-69, 70-79, 80-89, and $\geq 90$ years of age. Secondary outcomes were assessed separately for the outpatient visit assessment population and hospitalization assessment population. If a patient had multiple exacerbations requiring hospital admission, the last hospitalization during the study period was selected for analysis of HCRU and costs, provided the patient was discharged before the end of the study period.

\section{Statistical Analysis}

For the prevalence of severe asthma, counts and percentages were reported; 95\% confidence intervals (CIs) were estimated using the Wilson score method. SAS Release 9.4 or later (SAS Institute, Inc., Cary, NC, USA) was used in the analyses.

\section{RESULTS}

\section{Patient Population}

Data for 243,447 patients with claims for outpatient visits and 90,431 patients with claims for inpatient hospital visits were collected. Among those with outpatient visits, 35,742 were identified as having asthma, 4211 of whom met the criteria for severe asthma (Fig. 1).

Among 90,431 patients with claims for inpatient hospital visits, 4210 inpatients were identified as the hospitalization assessment population; 335 (8\%) had more than one asthma-related hospitalization (Fig. 1).

\section{Prevalence of Severe Asthma}

Overall, the prevalence of severe asthma among patients with asthma was $11.8 \%$ (Table 1 ). The proportion of patients with severe asthma was higher in patients $\geq 40$ years of age than in younger patients (Table 1). For example, the 


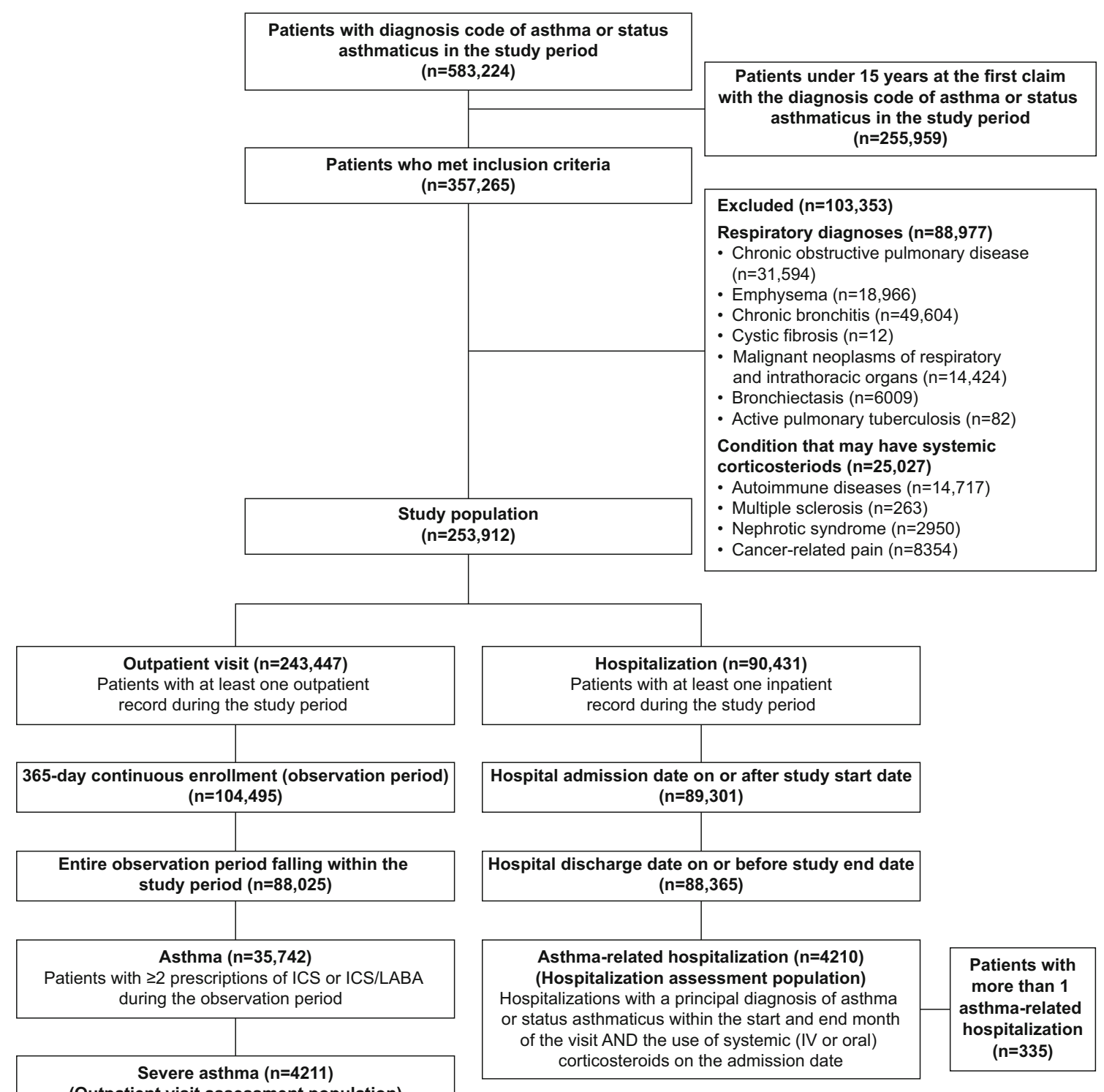

(Outpatient visit assessment population)

Patients with $\geq 240$-day prescription of high-dose

ICS and $\geq 190$-day prescription of one or more controller medications during the observation period

Fig. 1 Selection of Japanese patients with severe asthma and asthma exacerbations requiring hospitalization. The study period was 3 years, from 1 July 2014 to 30 June

prevalence of severe asthma was $12.0-13.4 \%$ across all 10-year subgroups from $\geq 40$ years of age, compared with $6.6-8.8 \%$ among the 15-19, 20-29, and 30-39 years age groups (Table 1). Among asthma patients aged 80 years or more, more than $10 \%$ patients identified as having severe asthma treated with high-dose ICS.
2017. ICS inhaled corticosteroids, $I V$ intravenous, $L A B A$ long-acting beta-agonist, $M D V$ Medical Data Vision, $C I$ confidence interval

\section{Patient Demographics, Clinical Characteristics, Asthma-Related HCRU, and Direct Costs (Outpatient Visit Assessment Population)}

The mean age of patients with severe asthma was 60.1 years, and $61.3 \%$ were female (Table 2). In the severe asthma population, 


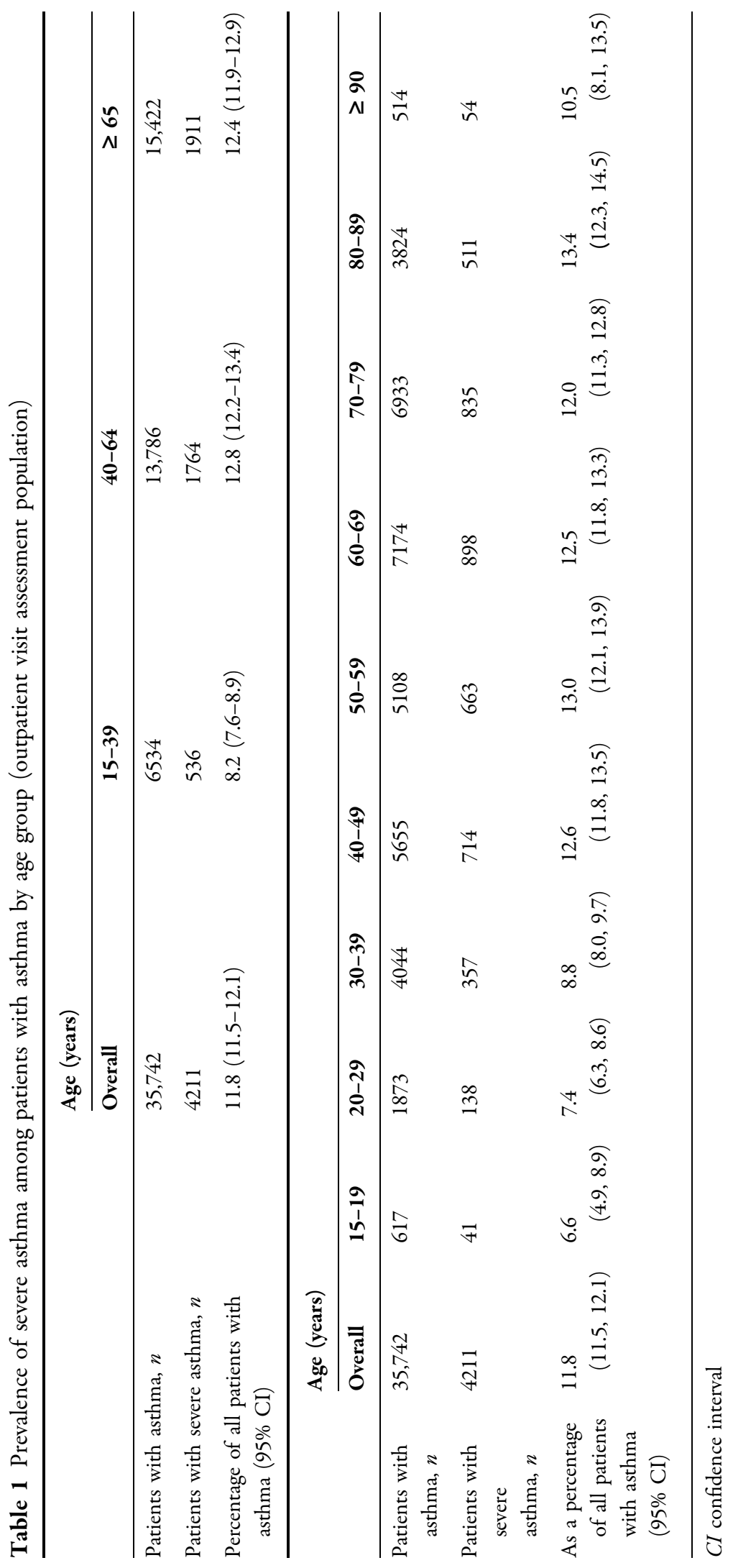


Table 2 Demographics and clinical characteristics of Japanese patients with severe asthma by age group (outpatient visit assessment population)

\begin{tabular}{|c|c|c|c|c|}
\hline & \multicolumn{4}{|l|}{ Age (years) } \\
\hline & Overall & $15-39$ & $40-64$ & $\geq 65$ \\
\hline$N$ & 4211 & 536 & 1764 & 1911 \\
\hline $\mathrm{Age}^{\mathrm{a}}$, years, mean $(\mathrm{SD})$ & $60.1(16.9)$ & $31.3(6.3)$ & $52.3(7.2)$ & $75.4(6.9)$ \\
\hline Female, $n(\%)$ & $2583(61.3)$ & $344(64.2)$ & $1063(60.3)$ & $1176(61.5)$ \\
\hline CCI score, mean (SD) & $2.0(1.6)$ & $1.3(0.7)$ & $1.7(1.2)$ & $2.5(1.9)$ \\
\hline \multicolumn{5}{|l|}{ Patients receiving asthma medication, $n(\%)$} \\
\hline ICS/LABA & $3971(94.3)$ & $521(97.2)$ & $1694(96.0)$ & $1756(91.9)$ \\
\hline LTRA & $2537(60.2)$ & $348(64.9)$ & $1113(63.1)$ & $1076(56.3)$ \\
\hline SABA & $1714(40.7)$ & $277(51.7)$ & $822(46.6)$ & $615(32.2)$ \\
\hline Theophylline & $1381(32.8)$ & $153(28.5)$ & $596(33.8)$ & $632(33.1)$ \\
\hline ICS & $481(11.4)$ & $56(10.4)$ & $173(9.8)$ & $252(13.2)$ \\
\hline LABA & $429(10.2)$ & $46(8.6)$ & $162(9.2)$ & $221(11.6)$ \\
\hline LAMA & $332(7.9)$ & $46(8.6)$ & $150(8.5)$ & $136(7.1)$ \\
\hline Anti-IgE monoclonal antibody & $59(1.4)$ & $12(2.2)$ & $29(1.6)$ & $18(0.9)$ \\
\hline Anti-IL-5 monoclonal antibody & $23(0.5)$ & $2(0.4)$ & $16(0.9)$ & $5(0.3)$ \\
\hline Using daily OCS ${ }^{\mathrm{b}}, n(\%)$ & $1310(31.1)$ & $183(34.1)$ & $612(34.7)$ & $515(26.9)$ \\
\hline Cumulative daily OCS dose, mean (SD) $\mathrm{mg} /$ year & $650.8(847.4)$ & $468.0(700.6)$ & $664.7(878.8)$ & $695.6(849.2)$ \\
\hline
\end{tabular}

CCI Charlson comorbidity index, ICS inhaled corticosteroids, Ig immunoglobulin, IL interleukin, LABA long-acting betaagonist, $L A M A$ long-acting muscarinic receptor antagonist, $L T R A$ leukotriene receptor antagonist, $N / n$ number of patients, $O C S$ oral corticosteroids, $S A B A$ short-acting beta-agonist, $S D$ standard deviation

${ }^{a}$ Age as of asthma index date

b Continuously prescribed a daily dose of $\geq 5 \mathrm{mg}$ prednisone equivalent. A persistent prescription was defined as continuous therapy renewed without a gap of more than 14 days. Unfilled prescriptions ('pill in the pocket') were excluded from the analysis

elderly patients ( $\geq 65$ years of age) had more than younger patients (15-39 and 40-64 years of age), as indicated by the mean (standard deviation) of Charlson comorbidity index (CCI) score. Compared with these younger age groups, a lower proportion of elderly patients with severe asthma were prescribed ICS/LABA, leukotriene receptor antagonists, short-acting beta-agonists, or daily oral corticosteroids (OCS); however, their cumulative dose of daily OCS was higher (Table 2). Although fewer elderly patients with severe asthma required emergency room (ER) visits compared with those of the two younger age groups, a higher proportion of elderly patients required biochemical, hematological, immunological, and microbiological testing compared with younger patients (Table 3). Conversely, the number of pulmonary function tests appeared to decrease with age; when assessing laboratory tests in greater detail (by nine age categories), only $24.9 \%$ and $5.6 \%$ of patients who were $80-89$ and $\geq 90$ years of age received a pulmonary function test, compared with $33.8-48.8 \%$ in the 
Table 3 Asthma-related HCRU ${ }^{a}$ of Japanese patients with severe asthma by age group (outpatient visit assessment population)

\begin{tabular}{lllllll}
\hline \multicolumn{1}{l}{ Age (years) } & & \\
\cline { 2 - 6 } & & Overall & $\mathbf{1 5 - 3 9}$ & $\mathbf{4 0 - 6 4}$ & $\mathbf{2 6 5}$ \\
\hline$N$ & 4211 & 536 & 1764 & 1911
\end{tabular}

Scheduled outpatient visits

Mean (SD) number of visits

$8.0(4.4) \quad 7.6(3.5) \quad 8.0(4.3) \quad 8.2(4.6)$

Asthma unscheduled outpatient visits (after-hours/late-night/holiday), $n(\%)$

Patients with $\geq 1$ visits, $n$ (\%)

$\begin{array}{llll}258(6.1) & 52(9.7) & 117(6.6) & 89(4.7) \\ 0.1(1.6) & 0.2(0.6) & 0.2(1.2) & 0.1(2.0)\end{array}$

Mean (SD) number of visits

Pulmonary function ${ }^{\mathrm{b}}$ tests

Patients with $\geq 1$ tests, $n$ (\%)

1467

Mean (SD) number of tests

Biochemical ${ }^{\mathrm{c}}$ tests

Patients with $\geq 1$ tests, $n$ (\%)

Mean (SD) number of tests

Hematological ${ }^{\mathrm{c}}$ tests

Patients with $\geq 1$ tests, $n$ (\%)

Mean (SD) number of tests

Immunological ${ }^{c}$ tests

Patients with $\geq 1$ tests, $n$ (\%)

Mean (SD) number of tests

Microbiological ${ }^{c}$ tests

Patients with $\geq 1$ tests, $n$ (\%)

Mean (SD) number of tests
$0.7(1.3) \quad 0.7(1.4) \quad 0.7(1.2) \quad 0.6(1.3)$

$\begin{array}{llll}2580 & 246 & 915 & 1419\end{array}$

$(61.3) \quad(45.9) \quad(51.9) \quad(74.3)$

$2.3(3.1) \quad 1.1(2.0) \quad 1.9(2.9) \quad 3.1(3.3)$

$\begin{array}{llll}2589 & 256 & 933 & 1400\end{array}$

$(61.5) \quad(47.8) \quad(52.9) \quad(73.3)$

$2.3(3.0) \quad 1.2(2.1) \quad 1.8(2.8) \quad 3.0(3.2)$

2229

$265 \quad 854$

1110

(49.4) (48.4)

$1.5(2.3) \quad 1.0(1.6) \quad 1.3(2.2) \quad 1.8(2.5)$

$524(12.4) \quad 58(10.8) \quad 181$

285 (14.9)

(10.3)

$0.2(0.6) \quad 0.1(0.5) \quad 0.1(0.5) \quad 0.2(0.7)$

FeNO fractional exhaled nitric oxide, $H C R U$ healthcare resource utilization, $N / n$ number of patients, $S D$ standard deviation

${ }^{a}$ HCRU calculated over a 1-year observation period

b Included vital capacity, flow volume testing, functional residual capacity/FeNO, multi-frequency oscillation tests

${ }^{c}$ Captured by the codes of medical management fees

younger groups. Direct asthma-related total outpatient costs (per patient), as well as individual component costs, increased with the increasing age groups (Fig. 2); medication costs 
were the primary driver. The total outpatient costs associated with severe asthma were $¥ 319,436$ for all patients, and $¥ 276,622$, $¥ 307,197$, and $¥ 342,742$, respectively, for patients who were $15-39,40-64$, and $\geq 65$ years of age. Among those patients who were 80-89 and $\geq 90$ years of age, total outpatient costs associated with severe asthma were $¥ 345,189$ and $¥ 319,476$, respectively.

\section{Patient Demographics, Clinical Characteristics, Asthma-Related HCRU, and Direct Costs (Hospitalization Assessment Population)}

Overall, the mean age of hospitalization assessment population was 57.2 years, and $66.1 \%$ were female (Table 4). Elderly patients ( $\geq 65$ years) with asthma-related hospitalizations had significantly more comorbidities than those who were 15-39 or 40-64 years of age, as indicated by the CCI score (Table 4). Compared with the other age groups analyzed, the proportions of patients who received treatment with antibiotics or OCS were highest among hospitalized patients $\geq 65$ and $40-64$ years of age (Table 4). The duration of asthma-related hospital stays numerically increased with age (range 6.4-11.0 days), especially among the 80-89 and $\geq 90$ age groups with 12.2 days and 13.2 days, respectively. Twenty-seven patients $(0.6 \%)$ died during asthma-related hospitalization. Among them, 11 patients were $80-89$ years of age, and 12 patients were $\geq 90$ years of age. With regards to laboratory tests, only the proportion of patients requiring microbiological tests appeared to increase with age (Table 4). Approximately one-third of patients $\geq 40$ years of age used ambulance transportation compared with just over one-fifth of those 15-39 years of age. Utilization of home medical care before a hospital admission was directly proportional to age (range $0.8-5.8 \%$ of patients). This was also the case for asthma-related hospitalization costs (per patient), with non-medication costs constituting the main component (Fig. 3); total asthma-related hospitalization costs (per event) were $¥ 274,583, \quad 326,821$ and $¥ 438,435$, respectively, for patients who were 15-39, $40-64$, and $\geq 65$ years of age.

\section{DISCUSSION}

This study evaluated the prevalence of severe asthma in Japanese patients over a broad age range, using real-world data from a large cohort included in a hospital-based database. Clinical characteristics, asthma-related HCRU, and direct costs were also assessed in patients with severe asthma and in those with asthma who experienced exacerbations requiring hospitalization. Among Japanese patients with asthma receiving maintenance therapy, severe asthma was more prevalent in those aged $\geq 40$ years than in those aged $15-39$ years; $\geq 10 \%$ of patients in each of the age groups $\geq 40$ years had severe asthma. Elderly patients $(\geq 65$ years of age) experienced the highest clinical burden in terms of comorbidities, cumulative daily OCS dose, home medical care before hospitalization, and the duration of hospital stay. Interestingly, most patients $\geq 80$ years of age had not undergone a pulmonary function test. Direct asthmarelated total outpatient and hospitalization costs (per patient) increased with age; of note, total hospitalization costs were highest for patients $\geq 80$ years of age. This study provides valuable information on the prevalence and burden of severe asthma in Japanese patients with asthma, with results suggesting that asthma management for elderly patients requires more consideration.

Recent studies have estimated the prevalence of severe asthma ranging from $2.4-12.7 \%$ in Japan; this variability may be explained by differences in the sources of patient data and the definitions of asthma used. One previous study used data from medical records collected by all types of facilities in a health insurance claims database managed by the Japan Medical Data Center (JMDC), which contained data from insured employees of large corporations and their family members [6]. The authors, using almost the same definitions as for the present study for asthma and severe asthma, determined that the prevalence of severe asthma was $2.4 \%$ among asthma patients. In that study, 
Table 4 Demographics, clinical characteristics, and HRU ${ }^{a}$ of Japanese patients who experienced asthma exacerbations requiring hospitalization by age group. (hospitalization assessment population)

\begin{tabular}{|c|c|c|c|c|}
\hline & \multicolumn{4}{|l|}{ Age (years) } \\
\hline & Overall & $15-39$ & $40-64$ & $\geq 65$ \\
\hline$N$ & 4210 & 997 & 1468 & 1745 \\
\hline Age at index date, years, mean (SD) & $57.2(21.3)$ & $28.3(7.5)$ & $51.6(7.2)$ & $78.5(7.8)$ \\
\hline Female, $n(\%)$ & $2784(66.1)$ & $565(56.7)$ & $902(61.4)$ & $1317(75.5)$ \\
\hline CCI score, mean (SD) & $1.5(0.9)$ & $1.1(0.4)$ & $1.4(0.7)$ & $1.9(1.0)$ \\
\hline Duration of hospital stay, mean (SD) days & $8.7(5.9)$ & $6.4(3.8)$ & $7.4(4.5)$ & $11.0(7.0)$ \\
\hline Death during hospitalization & $27(0.6)$ & $0(0.0)$ & $2(0.1)$ & $25(1.4)$ \\
\hline \multicolumn{5}{|l|}{ Patients receiving treatment for exacerbation, $n(\%)$} \\
\hline SABA (pMDI) & $223(5.3)$ & $61(6.1)$ & $95(6.5)$ & $67(3.8)$ \\
\hline SABA (inhalant liquid) by nebulizer & $3255(77.3)$ & $818(82.0)$ & $1144(77.9)$ & $1293(74.1)$ \\
\hline OCS & $299(7.1)$ & $62(6.2)$ & $119(8.1)$ & $118(6.8)$ \\
\hline ICS & $4125(98.0)$ & $978(98.1)$ & $1441(98.2)$ & $1706(97.8)$ \\
\hline Aminophylline (IV drip infusion) & $1276(30.3)$ & $287(28.8)$ & $474(32.3)$ & $515(29.5)$ \\
\hline LAMA (inhalation) & $80(1.9)$ & $13(1.3)$ & $37(2.5)$ & $30(1.7)$ \\
\hline $0.1 \%$ adrenaline (SC injection) & $241(5.7)$ & $65(6.5)$ & $106(7.2)$ & $70(4.0)$ \\
\hline Antibacterial agent & $1601(38.0)$ & $377(37.8)$ & $500(34.1)$ & $724(41.5)$ \\
\hline \multicolumn{5}{|l|}{ Patients with $\geq 1$ tests, $n(\%)$} \\
\hline Pulmonary function ${ }^{\mathrm{b}}$ tests & $674(16.0)$ & $167(16.8)$ & $271(18.5)$ & $236(13.5)$ \\
\hline Biological $^{\mathrm{c}}$ tests & $3358(79.8)$ & $794(79.6)$ & $1156(78.7)$ & $1408(80.7)$ \\
\hline Hematological $^{\mathrm{c}}$ tests & $3222(76.5)$ & $776(77.8)$ & $1125(76.6)$ & $1321(75.7)$ \\
\hline Immunological $^{\mathrm{c}}$ tests & $3224(76.6)$ & $760(76.2)$ & $1120(76.3)$ & $1344(77.0)$ \\
\hline Microbiological $^{\mathrm{c}}$ tests & $1140(27.1)$ & $219(22.0)$ & $379(25.8)$ & $542(31.1)$ \\
\hline \multicolumn{5}{|l|}{ Patients with additional requirements, $n$ (\%) } \\
\hline Unscheduled/emergency hospital admission & $4150(98.6)$ & $984(98.7)$ & $1444(98.4)$ & $1722(98.7)$ \\
\hline Ambulance transportation & $1327(31.5)$ & $228(22.9)$ & $494(33.7)$ & $605(34.7)$ \\
\hline Home medical care before hospital admission & $124(2.9)$ & $8(0.8)$ & $15(1.0)$ & $101(5.8)$ \\
\hline
\end{tabular}

$C C I$ Charlson comorbidity index, ICS intravenous corticosteroids, $I V$ intravenous, $L A M A$ long-acting muscarinic receptor antagonist, $N / n$ number of patients, $O C S$ oral corticosteroids, $p M D I$ pressurized metered-dose inhaler, $S A B A$ short-acting beta-agonist, $S C$ subcutaneous, $S D$ standard deviation

${ }^{\text {a }}$ HCRU calculated over the hospitalization period (pulmonary tests) or as of the hospital admission date (biochemical, hematological, immunological, and microbiological tests)

${ }^{b}$ Included vital capacity, flow volume testing, functional residual capacity/FeNO, multi-frequency oscillation tests

${ }^{c}$ Captured by the codes of medical management fees

$\mathrm{FeNO}$ fractional exhaled nitric oxide, $H C R U$ healthcare resource utilization, $N / n$ number of patients, $S D$ standard deviation 


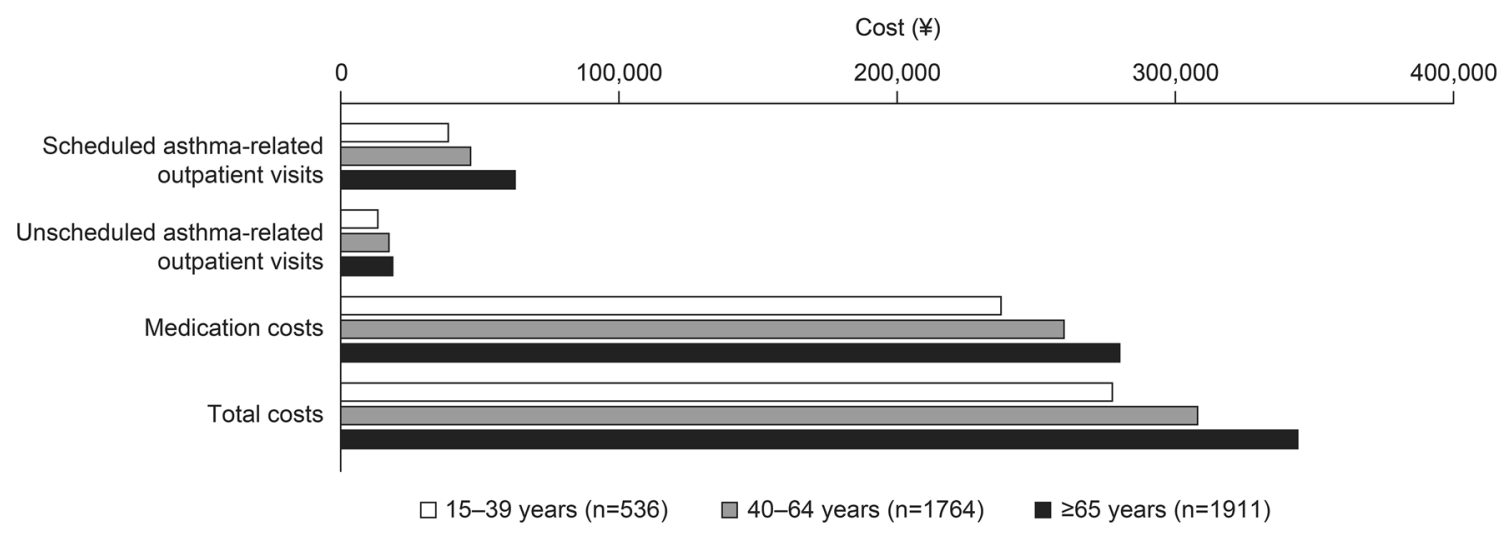

Fig. 2 Direct asthma-associated outpatient costs ${ }^{a}$ (patients/year) for severe asthma by age group (outpatient visit assessment population). ${ }^{a}$ Mean costs incurred over the 1 -year observation period

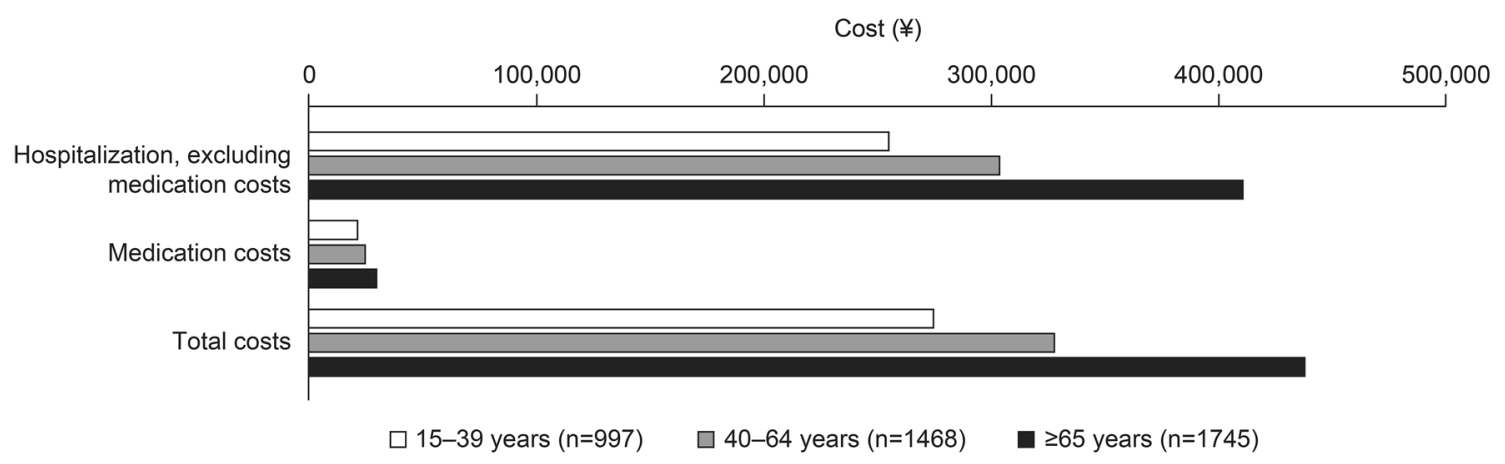

Fig. 3 Asthma-associated hospital costs ${ }^{a}$ (per event) for asthma by age group (hospitalization assessment population). ${ }^{a}$ Costs incurred over the 1-year observation period

most patients included were $<65$ years of age based on the Japanese health insurance system, and around $70 \%$ of patients with severe asthma had regularly received treatment at outpatient clinics. Meanwhile, the MDV database contains only records from hospitals; therefore, the outpatient visit assessment population of the present study may have included more severe cases than asthma patients in general and resulted in higher prevalence of severe asthma than those for the JMDC database study [6] across all comparable age categories.

This study also assessed the burden of outpatient visits for severe asthma. Compared with younger patients, those aged $\geq 65$ years with severe asthma had more concomitant diseases, higher cumulative daily OCS doses, and generally required more frequent blood tests. Among patients with asthma exacerbations requiring hospitalization, those aged $\geq 65$ years required more frequent home medical care before a hospital admission and those aged $\geq 40$ years required more frequent ambulance transportation.

As would be expected, hospitalized patients aged $\geq 65$ years had more comorbidities than younger patients in this study. Inoue et al. have reported that employed Japanese patients with severe asthma experienced substantial clinical and economic burden, tended to be older, and had more comorbidities than those with nonsevere asthma [15]. Their data on the duration of hospitalization and deaths during hospitalization have suggested that asthma-related hospitalization is a significant burden to elderly patients. These findings were supported by the results obtained from our present study, which was conducted in a population in which the 
observation was less likely to be censored by retirement or other factors. Our results further suggest that the burden of severe asthma increases with age.

We also found that for Japanese patients with severe asthma, asthma-associated total outpatient costs and hospitalization costs (per patient) increased with age. The total outpatient cost associated with severe asthma (¥319,436/patient/year) was similar to that previously reported by Nagasaki et al. (¥357,958/patient/year) [14]. Since Nagasaki et al. [14] estimated medical costs between 2013 and 2014 using claims data in Kyoto University Hospital, the characteristics of the study population might have been similar to those in our study. However, another retrospective cohort study conducted by Inoue et al. reported the total outpatient cost (comprising ER visits, outpatient visits, and prescriptions) of $¥ 141,515 /$ patient/year between 2009 and 2015; this discrepancy may be due to the study period. This discrepancy is also attributable to different databases used for the studies since Inoue et al. conducted their study using the JMDC database [15]. Therefore, caution should be observed in interpreting the medical costs. It has also been observed that for Japanese patients with severe asthma, those individuals whose symptoms are uncontrolled experience higher HCRU and associated costs than those whose symptoms are controlled [4]; therefore, it would be expected that optimizing the control of severe asthma in elderly patients would reduce asthma-associated HCRU and costs.

There are several limitations that should be noted for our study. First, the MDV database relies on administrative claims data and hospital discharge records for clinical details; therefore, data collection was subject to coding limits. Data capture may also have been incomplete owing to patients transfer between hospitals. Also, owing to the study design, patients who died were not included in our analysis. Since the source population included those treated in hospitals, not in outpatient clinics, the obtained data are not generalizable to the entire population of patients with severe asthma.
Because we used the prescription-based method for defining asthma severity, the severe asthma population of our study may have included some patients with moderate asthma receiving high-dose ICS and additional controller medications. Despite these limitations, our study provides an important assessment of the prevalence and burden of severe asthma in elderly Japanese patients.

In conclusion, the results of our study reaffirmed that severe asthma is more common among Japanese patients aged $\geq 40$ years than those aged $<40$ years and demonstrated a particularly high prevalence of severe asthma among patients aged 40 to $\geq 90$ years. Moreover, the study found that Japanese patients aged $\geq 65$ years, compared with younger ones, have greater clinical and economic burden due to severe asthma. This finding highlights the need for treatment options that help improve asthma control in elderly patients with severe asthma in Japan, which may ultimately lead to reductions in asthma-associated HCRU and costs in this patient population.

\section{ACKNOWLEDGEMENTS}

Funding. Sponsorship for this study and the Rapid Service Fee were funded by GlaxoSmithKline (GSK ID: HO-16-17890).

Medical Writing and/or Editorial Assistance. Editorial support (in the form of writing assistance, including development of the initial draft from the study report, assembling tables and figures, collating author comments, grammatical editing and referencing) was provided by Bianca Paris, PhD, of Fishawack Indicia Ltd, UK, and was funded by GSK K.K., Tokyo, Japan.

Authorship. All authors contributed to the conception or design of the study, the analysis and/or interpretation of the data, were involved in the preparation and review of the manuscript and also approved the final version for submission. All named authors meet the International Committee of Medical Journal Editors (ICMJE) 
criteria for authorship for this article, and take responsibility for the integrity of the work as a whole.

Disclosures. Keiko Sato is an employee of GSK and holds stock/shares in GSK. Takeo Ishii is an employee of GSK and holds stock/shares in GSK. Toshihiko Kaise is an employee of GSK, holds stock/shares in GSK, and receives pay for part-time lectureship at Shiga University of Medical Science. The authors would like to thank Clinical Study Support Inc. (Nagoya, Japan) for conducting data analyses and Tomoya Ohno from GSK for their support with study conception and design and data interpretation.

Compliance with Ethics Guidelines. The MDV database used in this analysis comprised de-identified, longitudinal, patient-level, administrative claims data for inpatients and outpatients, and hospital discharge records. Therefore, ethical approval was not required for this analysis. However, the study protocol was reviewed and approved by the independent ethics committee of Kitamachi Hospital (1-1-3 Kichijoji-kitamachi, Musashino, Tokyo, Japan). Since this was a retrospective cohort study using anonymized data extracted from a healthcare claims database, informed consent from patients was not required.

Data Availability. The datasets analyzed during the current study are available from the MDV database but are not publicly available because restrictions apply to the availability of these data, which were used under license for the current study. Data are, however, available from the authors upon reasonable request and with permission of the MDV database.

Open Access. This article is licensed under a Creative Commons Attribution-NonCommercial 4.0 International License, which permits any non-commercial use, sharing, adaptation, distribution and reproduction in any medium or format, as long as you give appropriate credit to the original author(s) and the source, provide a link to the Creative Commons licence, and indicate if changes were made. The images or other third party material in this article are included in the article's Creative Commons licence, unless indicated otherwise in a credit line to the material. If material is not included in the article's Creative Commons licence and your intended use is not permitted by statutory regulation or exceeds the permitted use, you will need to obtain permission directly from the copyright holder. To view a copy of this licence, visit http:// creativecommons.org/licenses/by-nc/4.0/.

\section{REFERENCES}

1. Chung KF, Wenzel SE, Brozek JL, et al. International ERS/ATS guidelines on definition, evaluation and treatment of severe asthma. Eur Respir J. 2014;43: 343-73.

2. Global Asthma Network. The Global Asthma Report 2018. https://globalasthmareport.org/Global\%20A sthma\%20Report\%202018.pdf. Accessed 1 June 2019.

3. Zein JG, Dweik RA, Comhair SA, et al. Asthma is more severe in older adults. PLoS ONE. 2015;10: e0133490.

4. Nagase H, Adachi M, Matsunaga K, et al. Prevalence, disease burden, and treatment reality of patients with severe, uncontrolled asthma in Japan. Allergol Int. 2020;69:53-60.

5. Adachi M, Hozawa S, Nishikawa M, Yoshida A, Jinnai T, Tamura G. Asthma control and quality of life in a real-life setting: a cross-sectional study of adult asthma patients in Japan (ACQUIRE-2). J Asthma. 2018;56:1106-25.

6. Sato K, Ohno T, Ishii $\mathrm{T}$, Ito $\mathrm{C}$, Kaise $\mathrm{T}$. The prevalence, characteristics, and patient burden of severe asthma determined by using a Japan health care claims database. Clin Ther. 2019;41:2239-51.

7. Zeiger RS, Schatz M, Dalal AA, et al. Utilization and costs of severe uncontrolled asthma in a managedcare setting. JACI In Pract. 2016;4(120-9):e3.

8. Chastek B, Korrer S, Nagar SP, et al. Economic burden of illness among patients with severe asthma in a managed care setting. J Manag Care Pharm. 2016;22:848-61.

9. Kerkhof M, Tran TN, Soriano JB, et al. Healthcare resource use and costs of severe, uncontrolled eosinophilic asthma in the UK general population. Thorax. 2018;73:116-24. 
10. United Nations: Department of Economic and Social Affairs. World population prospects: the 2017 revision, key findings and advance tables; 2017.

11. Muramatsu N, Akiyama H. Japan: super-aging society preparing for the future. Gerontologist. 2011;51:425-32.

12. Nakamura K. Diagnosis procedure combination database would develop nationwide clinical research in Japan. Circ J. 2016;80:2289-90.

13. Ichinose $M$, Sugiura $H$, Nagase $H$, et al. Japanese guidelines for adult asthma 2017. Allergol Int. 2017;66:163-89.
14. Nagasaki T, Sato K, Kume N, et al. The prevalence and disease burden of severe eosinophilic asthma in Japan. J Asthma. 2019;56:1147-58.

15. Inoue $H$, Kozawa $M$, Milligan KL, Funakubo $M$, Igarashi A, Loefroth E. A retrospective cohort study evaluating healthcare resource utilization in patients with asthma in Japan. NPJ Prim Care Respir Med. 2019;29:13. 